\title{
Electrochemical Studies of the Inhibition Effect of 4,6-dichloro- 2-(methylthio) pyrimidine on the Corrosion of AISI Type 321 Stainless Steel in 1.0 M Hydrochloric Acid
}

\author{
Rola Y. Khaled ${ }^{1}$, A.M. Abdel-Gaber ${ }^{1,2,}$, H. M. Holail ${ }^{3}$ \\ ${ }^{1}$ Department of Chemistry, Faculty of Science, Beirut Arab University, Lebanon \\ ${ }^{2}$ Department of Chemistry, Faculty of Science, Alexandria University, Ibrahimia, P.O. Box 426, \\ Alexandria 21321, EGYPT \\ ${ }^{3}$ Department of Geology, Faculty of Science, Alexandria University, Ibrahimia, P.O. Box 426, \\ Alexandria 21321, EGYPT \\ *E-mail: a.abdelgaber@bau.edu.lb, ashrafmoustafa@yahoo.com
}

doi: $10.20964 / 110402790$

Received: 7 January 2016 / Accepted: 21 January 2016 / Published: 1 March 2016

\begin{abstract}
The corrosion inhibition effect of 4,6-dichloro-2-(methylthio) pyrimidine (DCMTP) on AISI type 321 stainless steel in $1.0 \mathrm{M}$ hydrochloric acid solution at $30{ }^{\circ} \mathrm{C}$ was investigated using potentiodynamic polarization and electrochemical impedance spectroscopy (EIS) technique. Polarization curves showed that DCMTP acts as cathodic type inhibitor. The impedance response indicated that the corrosion process occurs under charge transfer control. Increasing inhibitor concentration led to significant reduction in the corrosion rate of stainless steel with achievable inhibition efficiency of $72 \%$ at $8 \times 10^{-4}$ M DCMTP. Activation parameters $\mathrm{E}_{\mathrm{a}}, \Delta \mathrm{H}^{*}$, and $\Delta \mathrm{S}^{*}$ were also calculated and discussed.
\end{abstract}

Keywords: AISI 321, Impedance, Polarization, inhibitor, activation parameters.

\section{FULL TEXT}

(C) 2016 The Authors. Published by ESG (www.electrochemsci.org). This article is an open access article distributed under the terms and conditions of the Creative Commons Attribution license (http://creativecommons.org/licenses/by/4.0/). 